Gut, 1977, 18, 45-47

\title{
Lactate dehydrogenase isoenzyme pattern in uninvolved mucosa of patients with colorectal carcinoma $^{1}$
}

\author{
ROSALIND TAYLER, V. H. CUMBERLAND, AND D. W. PIPER ${ }^{2}$ \\ From the Departments of Medicine and Gastroenterology, University of Sydney, The Royal North Shore \\ Hospital, Sydney, NSW, Australia
}

SUMMARY Colorectal mucosa from patients with colorectal carcinoma was compared with rectal mucosa from a control group. It was found that the LDH isoenzyme pattern of uninvolved mucosa proximal and distal to the carcinoma differed from that of normal tissue and resembled that of carcinoma tissue except in the case of the uninvolved mucosa proximal to the carcinoma of the sigmoid colon, which did not differ from normal mucosa.

An increased incidence of colorectal cancer is well documented with certain diseases such as familial polyposis and ulcerative colitis where a gross morphological lesion is obvious (Truelove and Reynell, 1972). A factor of greater importance is whether the mucosa in the vicinity of that from which the vast majority of colorectal carcinoma arises is abnormal despite its apparent normal gross histological appearance. The present study was undertaken to test this factor.

\section{Methods}

PATIENTS STUdied

Patients studied included 10 control subjects who had abdominal symptoms that justified sigmoidoscopy but in whom the rectal mucosa appeared to be normal and in whom barium enema was also normal; most were diagnosed as suffering from the spastic colon syndrome. An eleventh patient included in this group had a benign rectal polyp. Sixteen patients were suffering from histologically confirmed carcinoma of the large intestine; in nine, the carcinoma was in the rectum, in six it was in the sigmoid colon, and in one it was situated in

\footnotetext{
1This work was supported by the National Health and Medical Research Council of Australia, the New South Wales State Cancer Council, the University of Sydney Cancer Research Fund, and the J. N. Kirby Foundation.

${ }^{2}$ Address for correspondence: Professor D. W. Piper, Department of Medicine, Professorial Block, Royal North Shore Hospital, St. Leonards, NSW 2065, Australia.

Received for publication 6 August 1976
}

the caecum. Seven had ulcerative colitis, either diffuse or distal.

\section{TISSUE PROCUREMENT}

In the control patients, mucosa was obtained by rectal biopsy 15 to $20 \mathrm{~cm}$ from the anal margin. In those with carcinoma, mucosa was taken $10 \mathrm{~cm}$ proximal or distal to the neoplasm and it was confirmed histologically that the mucosa on the side of the sampled portion nearest to the tumour was not invaded by malignant tissue. Cancer tissue was taken from the edge of the neoplasm, care being taken to avoid necrotic tissue.

ASSAY PROCEDURES

Fifty milligrams of fresh mucosa were homogenised in $0.2 \mathrm{ml}$ tris-phosphate buffer ( $\mathrm{pH} \mathrm{7.4)}$ containing $2.0 \mathrm{mM}$ mercaptoethanol and centrifuged at $30000 \mathrm{~g}$ for 30 minutes at $4^{\circ} \mathrm{C}$.

The supernatant $(10-20 \mu \mathrm{l})$ was applied to a cellulose acetate strip and the isoenzymes were separated by electrophoresis at pH 8.6 (barbital buffer, ionic strength 0.075 ) at $4^{\circ} \mathrm{C}$. The isoenzyme bands were stained by the tetrazolium method (Preston, 1968). The strips were scanned at $468 \mathrm{~nm}$ using a Farrand Mark I spectrofluorometer. The areas under the peaks were measured and used to calculate proportion of skeletal muscle subunit and heart muscle subunit activities; these were expressed as the M/H ratio (Gerhardt et al., 1967)).

Results

The $\mathrm{LDH} \mathrm{M} / \mathrm{H}$ ratio is expressed in Table 1 . 
Findings are expressed for carcinoma of the sigmoid colon and rectum and for the whole series. Statistical analysis of the results using Student's $t$ test is shown in Table 2. The findings were as follows:

1. Cancer tissue had a higher $\mathrm{M} / \mathrm{H}$ ratio than the mucosa of control subjects and the mucosa proximal and distal to the cancer over the whole series and in those with sigmoid carcinoma; however, it did not differ from the proximal and distal mucosa of those with carcinoma of the rectum.

2. The distal mucosa of both cancer sites and the whole cancer series had a higher ratio than control mucosa.

3. The proximal mucosa of those with carcinoma of the rectum and of the whole series had a higher ratio than control mucosa, but the ratios in the proximal mucosa of those with sigmoid carcinoma and in control mucosa were statistically similar.

4. The mucosa of patients with inflammatory bowel disease had a higher $\mathrm{M} / \mathrm{H}$ ratio than controls $(\mathrm{P} \simeq 0.001)$.

5. The $\mathbf{M} / \mathrm{H}$ ratio did not differ when proximal mucosa, carcinoma tissue, and distal mucosa were compared in those with sigmoid and rectal carcinoma ( $P=0 \cdot 1,0 \cdot 4$, and 0.4 respectively).

\section{Discussion}

The findings demonstrating that cancer tissue differs from uninvolved tissue and that of non-cancer patients is of little significance at this stage because it has been demonstrated many times in many tissues (review by Schapira, 1973). The importance of the observations in this paper relate to the findings that certain uninvolved mucosa of cancer patients differs as regards the LDH isoenzyme pattern when compared with similar mucosa of non-cancer patients. Though a similar study has not previously been made, there is evidence from other workers consistent with these findings. Lewis et al. (1971) found that rectal biopsies from patients with ulcerative colitis in whom precancerous histological changes were present showed a change in the LDH isoenzyme pattern towards that of malignant tissue. In a study concerned with comparison of malignant tissues with uninvolved mucosa in patients with colorectal cancer, Briand and Fischerman (1973) observed that, in a few cases, $\mathrm{LDH}$ isoenzyme values of adjacent non-involved mucosa were at tumour level. Similar observations had previously been made by Langvad (1968) who subsequently found that those patients who had an LDH isoenzyme pattern resembling malignant tissue at the resection site more commonly had a local recurrence of the tumour in the subsequent five to seven years (Langvad, 1975).

Two questions arise from the observations presented in this paper. Firstly, do the changes observed

Table $1 M / H$ ratio of proximal and distal mucosa of patients with carcinoma of large intestine, of patients without organic bowel disease, and of patients with inflammatory bowel disease

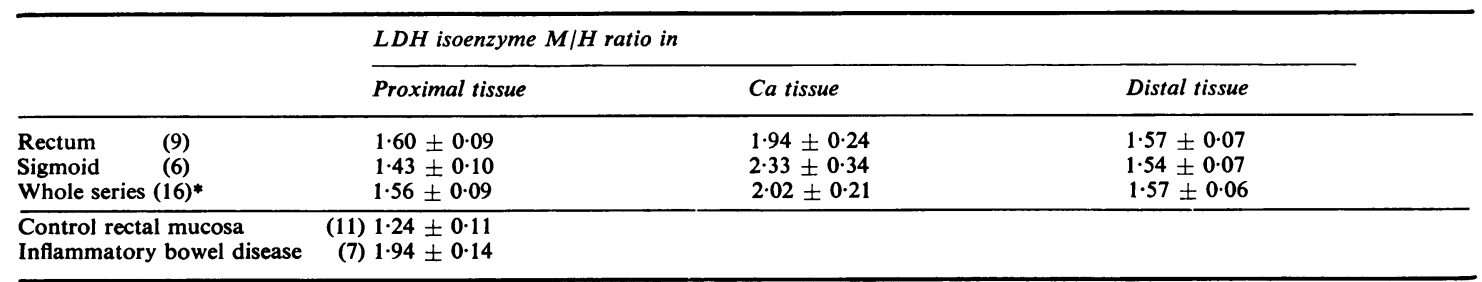

The number in parentheses indicates the number in each group.

*Includes one patient with carcinoma of the caecum

Table 2 Statistical analysis of results presented in Table 1

\begin{tabular}{|c|c|c|c|c|c|c|}
\hline \multirow[t]{2}{*}{ Comparison } & \multicolumn{6}{|l|}{$M / H$ ratio } \\
\hline & \multicolumn{2}{|c|}{ Sigmoid (6) } & \multicolumn{2}{|c|}{ Rectum (9) } & \multicolumn{2}{|c|}{ Whole series $(16)^{*}$} \\
\hline $\begin{array}{l}\text { Ca tissue v. proximal mucosa } \\
\text { Ca tissue v. distal mucosa } \\
\text { Ca tissue v. control mucosa } \\
\text { Proximal v. distal mucosa } \\
\text { Control v. proximal mucosa } \\
\text { Control v. distal mucosa }\end{array}$ & $\begin{array}{l}0.90(\mathrm{Ca}) \\
0.79 \text { (Ca) } \\
1.09 \text { (Ca) } \\
0.11 \text { (D) } \\
0.19 \text { (P) } \\
0.3 \text { (D) }\end{array}$ & $\begin{array}{l}<0.05 \\
<0.05 \\
<0.005 \\
0.4 \\
0.2 \\
<0.05\end{array}$ & $\begin{array}{l}0 \cdot 25(\mathrm{Ca}) \\
0 \cdot 37(\mathrm{Ca}) \\
0 \cdot 70(\mathrm{Ca}) \\
0 \cdot 12(\mathrm{P}) \\
0 \cdot 45(\mathrm{P}) \\
0 \cdot 32(\mathrm{D})\end{array}$ & $\begin{array}{c}0.3 \\
\simeq 0.2 \\
<0.02 \\
0.3 \\
<0.001 \\
0.02\end{array}$ & $\begin{array}{l}0.46(\mathrm{Ca}) \\
0.45(\mathrm{Ca}) \\
0.78(\mathrm{Ca}) \\
0.01 \text { (D) } \\
0.32 \text { (P) } \\
0.33 \text { (D) }\end{array}$ & $\begin{array}{l}0.05 \\
0.05 \\
0.005 \\
0.9 \\
0.04 \\
0.02\end{array}$ \\
\hline
\end{tabular}

The letters in parentheses $(\mathrm{Ca} \rightarrow$ cancer; $\mathrm{D} \rightarrow$ distal mucosa $\mathrm{P} \rightarrow$ proximal mucosa) indicate the mucosa with the higher ratio.

*Includes one patient with carcinoma of the caecum 
merely indicate a gradual fall in the $\mathrm{M} / \mathrm{H}$ ratio along the length of the normal colon as the control biopsies were taken from the distal $20 \mathrm{~cm}$ of the rectum and the tissue proximal and distal to the cancer were taken at higher levels? However, when the ratio is plotted for the proximal and distal tissues taken at different levels no such trend is present and that of the mucosa proximal to the sigmoid carcinoma $(\mathrm{M} / \mathrm{H}$ ratio $1.43 \pm 0 \cdot 10)$ does not differ significantly from that of the mucosa distal to rectal carcinoma $(1.57 \pm 0.07)(P=0.3)$. Secondly, how do these changes relate to the abnormalities in mucus and enzyme histochemistry in the apparently normal mucosa surrounding the carcinoma described by Filipe (1969), Filipe and Branfoot (1964), and Marsden and Dawson (1974)? These workers found that these changes extended $5-10 \mathrm{~cm}$ on either side of the lesion, but did not compare the changes with tissue from normal colons. It is not possible from our data to answer this question, but, whereas the changes described by Dawson and his colleagues were equally distributed on each side of the cancer, in the case of sigmoid cancer in the present series the abnormality in the LDH isoenzyme pattern was present only on the distal side of the lesion. Clearly, both series of studies need extending and coordinating, as the data may provide a clue to the premalignant biochemical state in patients with carcinoma of the colon.

If perchance the abnormal findings had been only proximal to the carcinoma, they could be attributed to inflammatory changes secondary to partial obstruction. However, it is noted in the present study that mucosa proximal to the sigmoid carcinoma site resembles control tissue, whereas all tissue distal to the site, be it cancer tissue or that distal to the sigmoid cancer, or proximal or distal to the rectal cancer, had an $\mathrm{M} / \mathrm{H}$ ratio different from control mucosa. It could therefore be postulated that the site of the sigmoid cancer indicates the beginning of a segment of colon that possesses a premalignant biochemical lesion, and carcinoma occurs at or beyond this site because of this possible premalignant change and the contact with the mucosa of colonic carcinogens in the form of bile salts, etc., present in the faeces (Hill, 1974). The occurrence of a focal lesion near a junctional zone has an analogy in the siting of gastric ulceration which occurs just distal to the junction of body and antral mucosa (Oi et al., 1969). This concept is consistent with the observation of Langvad and James (1975) who found that those patients who have an abnormal LDH M/H ratio more commonly developed recurrent cancer after resection. Finally, it cannot be assumed from the present study that the LDH M/H ratio found in patients with inflammatory bowel disease is a precursor of malignancy because other variables such as inflammation itself may be responsible.

\section{References}

Briand, P., and Fischerman, K. (1973). The activity of phosphofructokinase and lactate dehydrogenase in cancer of the colon and rectum and the effect of iodine on the normal mucosa. Acta Chirurgica Scandinavica, 139, 666-670.

Gerhardt, W., Clausen, J., Christensen, E., and Riishede, J. (1967). Lactate dehydrogenase isoenzymes in the diagnosis of human benign and malignant brain tumours. Iournal of the National Cancer Institute, 38, 343-357.

Hill, M. J. (1974). Colon cancer: a disease of fibre depletion or of dietary excess? Digestion, 11, 289-306.

Filipe, M. Isabel (1969). Value of histochemical reactions for mucosubstances in the diagnosis of certain pathological conditions of the colon and rectum. Gut, 10, 577-586.

Filipe, M. I., and Branfoot, A. C. (1974). Abnormal patterns of mucus secretion in apparently normal mucosa of large intestine with carcinoma. Cancer, 34, 282-290.

Langvad, E. (1968). Lactate dehydrogenase isoenzyme patterns in the tumour bearing colon. International Journal of Cancer, 3, 17-29.

Langvad, E., and Jemec, B. (1975). Prediction of local recurrence in colorectal carcinoma: an LDH isoenzyme assay. British Journal of Cancer, 31, 661-64.

Lewis, B., Morson, B. C., February, A. W., Hywel Jones, J., and Misiewicz, J. J. (1971). Abnormal lactic dehydrogenase isoenzyme patterns in ulcerative colitis with precancerous change. Gut, 12, 16-19.

Marsden, J. R., and Dawson, I. M. P. (1974). An investigation into enzyme histochemistry of adenocarcinomas of human large intestine and of the transitional epithelium immediately adjacent to them. Gut, 15, 783-787.

Oi, M., Ito, Y., Kumagai, F., Yoshida, F., Tanaka, Y., Yoshikawa, K., Miho, O., and Kigima, M. (1969). A possible dual control mechanism in the origin of peptic ulcer. A study on ulcer location as affected by mucosa and musculature. Gastroenterology, 57, 280-293.

Preston, J. A., Briere, R. O., and Batsakis, J. G. (1965). Rapid electrophoretic separation of lactate dehydrogenase isoenzymes on cellulose acetate. American Journal of Clinical Pathology, 43, 256-260.

Schapira, F. (1973). Isoenzymes and cancer. In Advances in Cancer Research, vol. 18, pp. 77-153. Edited by G. Klein, S. Weinhouse, and A. Haddow, Academic Press: New York.

Truelove, S. C., and Reynell, P. C. (1972). Diseases of the Digestive System, 2nd edn, pp. 469. Blackwell: Oxford. 